\title{
Vertical transmission of hepatitis B virus: challenges and solutions
}

\author{
This article was published in the following Dove Press journal: \\ International Journal of Women's Health \\ 10 June 2014 \\ Number of times this article has been viewed
}

\author{
Ivan Gentile \\ Guglielmo Borgia \\ Department of Clinical Medicine \\ and Surgery, University of Naples \\ "Federico II", Naples, Italy
}

Correspondence: Ivan Gentile Department of Clinical Medicine and Surgery (Ed I8), University of Naples "Federico II", via S Pansini 5, I-80 I 3 I Naples, Italy

Tel +3908I 7463178

$\mathrm{Fax}+390817463190$

Email ivan.gentile@unina.it
Abstract: More than 240 million people worldwide are chronically infected with hepatitis B virus (HBV). Mother-to-child transmission remains the most important mechanism of infection in countries with a high prevalence of HBV. Universal screening of all pregnant women, at-birth prophylaxis with specific anti-HBV immune globulin, as well as HBV vaccination for newborns of infected mothers are effective in reducing the risk of vertical transmission. However, in cases of a high viral load and hepatitis B e antigen positivity, there is a residual risk of HBV transmission to the newborn despite prophylaxis. This review focuses on the aboveindicated strategies and on the efficacy and safety of antiviral drugs administered during the third trimester of pregnancy.

Keywords: immune globulin, prophylaxis, telbuvidine, tenofovir, vaccine, viral load

\section{Introduction}

Hepatitis B virus (HBV) is a deoxyribonucleic acid (DNA) virus that, according to World Health Organization estimates, chronically infects more than 240 million people worldwide. ${ }^{1}$ In highly endemic countries, mother-to-child transmission accounts for most cases of infections and is, therefore, the main mechanism that perpetuates the infection in the population. ${ }^{2-4} \mathrm{HBV}$ is associated with a global burden of about 600,000 deaths a year. ${ }^{1} \mathrm{HBV}$ causes an acute hepatitis that becomes chronic in a percentage that is highly dependent on age of acquisition of the infection. ${ }^{5-7} \mathrm{In}$ fact, the rate of chronicity is about $90 \%$ in infants infected at birth or during the first year of life, $30 \%-50 \%$ in children aged $1-6$ years, and 5\%-10\% in children above 6 years of age and in adults. ${ }^{1,2}$ Once chronic hepatitis is established, a percentage ranging from $15 \%-40 \%$ evolve to liver cirrhosis and hepatocellular carcinoma. ${ }^{8-12}$ Finally, HBV is also associated with extrahepatic diseases. ${ }^{13-16}$

HBV infection during pregnancy poses particular problems. These include the effect of HBV infection on pregnancy, the effect of pregnancy on HBV infection, the mother-to-child transmission of HBV, and the management of drugs. ${ }^{2}$ The aim of this review was to examine recent studies that have been devoted to the vertical transmission of $\mathrm{HBV}$, and to examine in detail the current risk of transmission and the strategies that can reduce or ideally eliminate this risk.

\section{Vertical HBV transmission Definition}

Vertical transmission of $\mathrm{HBV}$ is defined as positivity at $6-12$ months of life of the hepatitis B surface antigen (HBsAg) or of HBV-DNA in an infant born to an infected mother. ${ }^{2,17}$ 
In fact, detection of the infection when the child is 6 months old correlates with infection when the child is 1 year old and indicates chronicity of the infection. ${ }^{17,18}$ The presence of both HBsAg and HBV-DNA at birth are often transitory events and do not imply transmission of the infection. ${ }^{17,19}$ Similarly, the presence of antibodies against hepatitis B e antigen or antibodies against Hepatitis B core antigen at birth or up to 2 years of age is simply due to their crossing the placenta from the mother to the fetus, and therefore is unrelated to infection. ${ }^{20}$

\section{Risk of transmission}

Without prophylaxis, the risk of HBV vertical transmission is high. The risk is highest in HBsAg- and HBeAg-positive mothers (transmission rate: 70\%-90\%), and low for HBsAgpositive $\mathrm{HBeAg-negative} \mathrm{mothers} \mathrm{(transmission} \mathrm{rate:}$ $10 \%-40 \%)^{2,21,22}$

At birth, prophylaxis is able to greatly reduce the risk of vertical transmission. ${ }^{22,23}$ It is currently administered to all HBsAg-positive mothers in most countries, and consists of both passive and active immunoprophylaxis., ${ }^{2,22,23}$ In detail, newborns of HBsAg-positive mothers receive both hepatitis B immune globulin (HBIG) (passive immunoprophylaxis) and the first dose of the HBV vaccine (active prophylaxis). ${ }^{22,23}$ In general, the first dose of the hepatitis B vaccine and HBIG should be given within 24 hours of the child being born. ${ }^{23}$ The vaccine schedule is completed with the administration of two or three doses of vaccine in the first 6 months of life. ${ }^{21}$ This combination scheme has been demonstrated to be more effective than the administration of either the HBV vaccine or HBIG alone. ${ }^{24,25}$ However, even using this combination strategy there is a residual risk of vertical transmission - namely, about 3\%. ${ }^{17,26-29}$ However, all cases of transmission that occur despite adequate prophylaxis are associated with a high maternal viral load and maternal HBeAg positivity. ${ }^{17,26-29}$ Indeed, a maternal viral load below $10^{6} \mathrm{IU} / \mathrm{mL}$ is not associated with vertical transmission, ${ }^{30}$ whereas the risk of transmission is about $3 \%$ in cases of a maternal viral load $10^{6}-10^{7}$ copies $/ \mathrm{mL}$, about $7 \%$ for a viral load $10^{7}-10^{8}$ copies $/ \mathrm{mL}$, and about $8 \%$ for a viral load $>10^{8}$ copies $/ \mathrm{mL}{ }^{29}$ These results were confirmed in an Australian study that reported a transmission rate of $9 \%$ in mothers with a viral load $>10^{8}$ copies $/ \mathrm{mL} .^{28}$ Finally, menstrual irregularity and severe nausea during the first trimester of pregnancy were found to be independently associated with a high risk of vertical transmission. ${ }^{31}$

\section{Mechanisms of transmission}

An understanding of the mechanisms of HBV transmission during pregnancy is important because preventive strategies aim at targeting these mechanisms. Mother-to-child transmission of HBV can occur via three modalities: intrauterine transmission; transmission during delivery; and postpartum transmission.

Intrauterine transmission accounts for only a minority of cases of HBV transmission..$^{21,32}$ In fact, a Chinese study showed an intrauterine infection rate of $3.7 \%$ in a sample of 402 newborn infants of HBsAg-positive mothers. ${ }^{32} \mathrm{~A}$ high viral load and positivity of HBeAg were factors associated with an increased risk of transmission through this route. ${ }^{32}$ Intrauterine transmission can occur in two ways: HBV can reach the fetus by crossing the placental barrier; and during its passage, HBV can infect and replicate in all types of placental cells before it reaches the fetus. ${ }^{32-34}$ It is noteworthy that the percent of infected cells decreases from the maternal side $(43.6 \%)$ to the fetus side $(18.8 \%)$ of the placenta. ${ }^{32}$ Finally, HBV may reach the fetus through transplacental leakage of the maternal blood into fetal circulation, a condition that is associated with prolonged threatened preterm labor or threatened abortion due to increased uterine contractions. ${ }^{21,32}$

Transmission of HBV during delivery is the most frequent method of vertical transmission. It is mostly due to newborn contact with the mother's infected secretions or blood at the time of delivery. ${ }^{21}$

A proportion of babies (as high as 34\%) may acquire infection after birth due to close contact with the mother. ${ }^{22}$ However, breastfeeding is not a risk factor for $\mathrm{HBV}$ infection. ${ }^{21,35-38}$

Given these three mechanisms, passive/active at-birth prophylaxis can prevent transmission during delivery or in the postpartum period, but it has no effect on the intrauterine route of transmission. Based on evidence from pathological studies of an infection gradient from the maternal to the fetal side of the placenta, and on the high rate of intrauterine infection in the event of a high maternal viral load, it is feasible that the placenta acts as a filter that is crossed only in case of a high maternal viral load.

Finally, due to the residual risk of HBV vertical transmission, despite correct at-birth prophylaxis with $\mathrm{HBIG}$ and vaccine, other strategies have been tested in this setting (namely, antiviral drugs, HBIG to the mother, and mode of delivery).

\section{Antiviral prophylaxis}

Various studies have explored the possibility of reducing HBV vertical transmission using antivirals during the third trimester of pregnancy. ${ }^{2}$ Currently available antivirals active against HBV are: interferon; pegylated interferon; and the nucleoside/ 
nucleotide analogs lamivudine, adefovir, telbivudine, enecavir, and tenofovir. ${ }^{2}$ Of these, interferon and pegylated interferon are classified in pregnancy class X (ie, studies on animals or humans have revealed fetal abnormalities), and are therefore strongly contraindicated during pregnancy. ${ }^{21}$ Lamivudine, entecavir, and adefovir are in pregnancy class $\mathrm{C}$ (animal studies revealed embryo or fetal toxicity in animals, but not in humans). ${ }^{21}$ Finally, telbivudine and tenofovir are in pregnancy class B (no risk of fetal toxicity has been found in animal studies or in humans, but complete safety cannot be ensured due to the lack of adequate studies conducted with pregnant women). ${ }^{21}$

Safety data on nucleoside or nucleotide analogs are reassuring. The Antiretroviral Pregnancy Registry is an international voluntary registry that has been collecting data about the safety of antiretroviral drugs during pregnancy since 1989. ${ }^{39}$ According to data posted in this registry (see Table 1), the rate of birth defects in women taking antiretroviral drugs during pregnancy is similar to that of the general population (about 3\%). Given the safety of these drugs during pregnancy, several studies have evaluated the efficacy of antiviral drugs in reducing the $\mathrm{HBV}$ vertical transmission rate particularly in women with a high viral load. ${ }^{40-42,45,46,48,49}$ The first drug tested was lamivudine. In a pilot trial, eight HBV-infected mothers with a high viral load were treated with lamivudine at a dose of $150 \mathrm{mg}$ daily in the last month of pregnancy. ${ }^{40}$ Twenty-four children born to HBV-infected mothers with similar characteristics acted as historical controls. The rate of transmission, despite passive/active prophylaxis at birth, was $12.5 \%$ in the lamivudine group and $28 \%$ in untreated controls. ${ }^{40}$ Based on this study, a large randomized controlled trial evaluated the efficacy of lamivudine administered at a dose of $100 \mathrm{mg}$ daily from week 32 of pregnancy to week 4 postpartum in preventing vertical transmission in 150 mothers (149 of whom were HBeAg-positive) with a high viral load (HBV-DNA $>1,000 \mathrm{mEq} / \mathrm{mL}){ }^{41}$ In intention-to-treat analysis, the rate of HBsAg in babies at week 52 was $18 \%$ in the lamivudine arm and $39 \%$ in the placebo arm. Similarly,

Table I Birth defect rate and $95 \% \mathrm{Cl}$ from the Antiretroviral Pregnancy Registry concerning lamivudine, tenofovir, telbivudine, and entecavir

\begin{tabular}{lll}
\hline & First trimester & Second/third trimester \\
\hline LMV & I $36 / 4.360(3.1 \%) ;$ & $203 / 7,072(2.9 \%) ;$ \\
& $95 \% \mathrm{Cl}: 2.6 \%-3.7 \%$ & $95 \% \mathrm{Cl}: 2.5 \%-3.3 \%$ \\
TDF & $46 / 1,982(2.3 \%) ;$ & $20 / 959(2.1 \%) ;$ \\
& $95 \% \mathrm{Cl}: 1.7 \%-3.1 \%$ & $95 \% \mathrm{Cl}: 1.3 \%-3.2 \%$ \\
TLB & $0 / 10$ & $0 / 14$ \\
ETV & $2 / 55$ & $0 / 2$ \\
\hline
\end{tabular}

Abbreviations: $\mathrm{Cl}$, confidence itnerval; LMV, lamivudine; TDF, tenofovir disoproxilfumarate; TLB, telbivudine; ETV, entecavir. the rate of HBV-DNA positivity at the same time point was $20 \%$ versus $59 \%$ in the lamivudine versus placebo arm. ${ }^{41}$ However, the drop-out rate was extremely high $(13 \%$ in the lamivudine arm, $31 \%$ in the placebo arm) and this probably influenced the results. ${ }^{2,41}$ Finally, the safety of the drug was good.

An observational study from Australia explored the efficacy of lamivudine administered in the third trimester of pregnancy in 21 women with a high viral load $\left(>10^{7} \mathrm{IU} / \mathrm{mL}\right)$ compared to five untreated pregnant women who served as a control group. ${ }^{42}$ The median decrease in viral load was 2.6 $\log _{10} \mathrm{IU} / \mathrm{mL}$ in the lamivudine group, but in $18 \%$ of cases, HBV-DNA remained $>10^{7}$ at the end of treatment. Nevertheless, no case of mother-to-child transmission was observed in the lamivudine-group versus one case in the control group. Notably, using a very sensitive technique (ultra-deep pyrosequencing) viral variants with reduced sensitivity to lamivudine (substitutions in codons 204 and 181) were observed in four women $(19 \%)$. Therefore, based on this study, lamivudine administration during the third trimester has poor antiviral activity, and even a brief period of administration can select resistance mutations. These results confirm the low barrier to resistance of lamivudine also in the setting of pregnancy. ${ }^{8}$

Given the limitations of lamivudine, several trials were performed using telbivudine, which is a nucleoside ana$\log$ that has a higher antiviral power than lamivudine. ${ }^{43,44}$ In a study carried out in the People's Republic of China, 229 HBeAg-positive pregnant women with HBV-DNA levels $>10^{7}$ copies $/ \mathrm{mL}$ received telbivudine at a dose of 600 mg daily (number $[\mathrm{n}]=135$ ) or acted as untreated controls ( $n=94)$ based on their choice. ${ }^{45}$ Telbivudine treatment started from 20-32 weeks of gestation and continued up to 4 weeks after delivery (or 28 weeks after delivery in case of the baseline elevation of alanine aminotransferase). All treated mothers had a more than $3 \operatorname{logs}{ }_{10} \mathrm{IU} / \mathrm{mL}$ decline in viral load before delivery, and HBV-DNA was undetectable in 33\% of the treated mothers compared to $0 \%$ of the untreated controls. All babies received the combined $\mathrm{HBIG}$ /vaccine prophylaxis. The rate of HBsAg positivity in babies at 28 weeks of age was $0 \%$ in the telbivudine group and $8 \%$ in untreated controls. No serious adverse events were recorded in the mothers or in their children in either group, and the Apgar index, as well as the weight and height at birth was similar in the two groups, as was the rate of cesarean section. No birth defects occurred in either group. ${ }^{45}$

The efficacy and safety of telbivudine administration in high viral load mothers in late pregnancy to prevent vertical 
transmission was confirmed in a meta-analysis that analyzed six studies (two randomized controlled trials and four nonrandomized controlled trials) for a total of 576 pregnant women. ${ }^{46}$ However, the authors' final recommendation was that high quality, large-sized randomized controlled trials are needed to ensure that a final decision is reached regarding the administration of telbivudine to prevent the vertical transmission of $\mathrm{HBV}^{46}$

Finally, tenofovir is a potent antiviral that acts against HBV with a high barrier to resistance. ${ }^{47} \mathrm{~A}$ retrospective study evaluated the efficacy of tenofovir administered in the third trimester of pregnancy at a dose of $300 \mathrm{mg}$ once daily to eleven women with high viremia $\left(>10^{6}\right.$ copies $\left./ \mathrm{mL}\right) .{ }^{48}$ The mean maternal viral load declined from $8.87 \log _{10}$ copies/mL at baseline to $5.25 \log _{10}$ copies/mL at the time of delivery. All of the eleven infants received passive/active prophylaxis, and none of them were HBsAg-positive at 28-36 weeks of age. ${ }^{48}$ No obstetric complications or birth defects were recorded.

A second retrospective study enrolled $45 \mathrm{HBeAg-}$ positive pregnant women with high viral loads (HBVDNA $>10^{7}$ copies $\left./ \mathrm{mL}\right) ; 21$ of them were treated with tenofovir from week 18-27 of gestation, and 24 of them were untreated and served as controls. ${ }^{49}$ All infants received standard passive/active prophylaxis. At 28 weeks of age, $\mathrm{HBsAg}$ was detected in two $(8.3 \%)$ babies of untreated mothers, but not in any of the babies of treated mothers $(P=0.022)$. The two groups of babies did not differ in terms of adverse events, birth defects, height, or weight. Twenty-eight weeks after delivery, HBV-DNA was undetectable in $62 \%$ of the treated mothers, whereas HBV-DNA was detected in all of the controls $(P<0.001)$. However, as yet, no randomized controlled trial study has evaluated the use of tenofovir to prevent vertical transmission.

\section{Other strategies to reduce vertical transmission Hepatitis B immunoglobulin administration during pregnancy}

A meta-analysis evaluated the efficacy and safety of periodical HBIG administration to the mother during pregnancy to prevent vertical transmission. ${ }^{50}$ Nine randomized controlled trials that enrolled a total of 2,149 infants from HBsAg-positive mothers were included in the analysis for the evaluation of vertical transmission, which was defined as positivity for HBsAg 9-12 months after birth. Periodical HBIG administration to the mother during pregnancy had a protective effect (odds ratio $=0.33$ ).${ }^{50}$ However, these results should be viewed in the light of the heterogeneity of dosages (200 IU or $400 \mathrm{IU})$, and of the populations enrolled. Consequently, the periodic administration of HBIG to the mother to prevent vertical transmission is not currently recommended. ${ }^{21}$

\section{Type of delivery}

Several groups have evaluated whether elective cesarean section prevents HBV vertical transmission. ${ }^{18,51-53}$ The results of these studies are conflicting. An observational study of 301 newborns ( 144 born by vaginal delivery, 40 by forceps, and 117 by cesarean section) in the People's Republic of China showed a similar rate of vertical transmission (defined as $\mathrm{HBsAg}$ presence at 1 year of age) in infants born to HBsAg-positive mothers (and who underwent the standard prophylaxis) according to the mode of delivery (3\%, 7.7\%, and $6.8 \%$ in the vaginal, forceps, and cesarean groups, respectively).$^{51}$ In contrast, a meta-analysis of four randomized controlled trials that enrolled a total of 789 pregnant women showed that elective cesarean section (ie, before labor or the rupture of membranes) was associated with a lower rate of transmission (10.5\%) compared with vaginal delivery $(28 \%) .{ }^{52}$ However, the authors recommend that their findings be interpreted with caution due to the high risk of bias of the studies included in the analysis. ${ }^{52}$ Finally, a retrospective study identified a similar rate of $\mathrm{HBV}$ chronic infection in 546 children aged 1-7 years in diverse types of delivery $(2.5 \%$ in children born by elective cesarean section and $2.3 \%$ in those born by vaginal delivery). ${ }^{53}$

Therefore, due to a lack of evidence and to the well-known high rate of complications with cesarean section compared to spontaneous vaginal delivery, we do not recommend this procedure be used to reduce HBV vertical transmission.

\section{Discussion}

If we consider the three major viral infections ( $\mathrm{HBV}, \mathrm{HCV}$, and human immunodeficiency virus [HIV]), the management of $\mathrm{HBV}$ infection in pregnancy is similar to the management of $\mathrm{HIV}$; indeed, both entail the long-term use of antivirals and the need to balance the safety of the fetus and the efficacy of treatment. ${ }^{54}$ However, HCV infection is associated with a non-negligible rate of vertical transmission (about 3\%-5\%). ${ }^{55}$ In patients with $\mathrm{HCV}$ infection, antiviral therapy should be administered before pregnancy in an attempt to achieve viral clearance, which strongly reduces the risk of transmission. Treatment during pregnancy is contraindicated because of the well-known teratogenic effect of ribavirin, which is an essential component of anti-HCV treatment. However, the problem of vertical transmission remains for cases of $\mathrm{HCV}$ infection 
that are discovered at the time of pregnancy. Notably, none of the new antiviral drugs active against $\mathrm{HCV}$ have been tested during pregnancy, not even in animal models. ${ }^{56-62}$

The prevention of HBV vertical transmission is a complex task and involves both gynecologists and infectious diseases specialists. Importantly, the universal screening of all pregnant women for HBsAg is essential in preventing the vertical transmission of $\mathrm{HBV}^{2}$ In fact, the early identification of one's HBsAg status enables the timely administration of passive/active prophylaxis to the newborn. Besides being the most important measure in preventing vertical transmission, universal HBsAg screening of pregnant women is also costeffective. ${ }^{63,64}$ Unfortunately, screening programs are not totally efficient, even in Western countries. For example, an Italian study showed that $2.3 \%$ of a sample of 17,260 women did not undergo screening for $\mathrm{HBV}$ infection during pregnancy. ${ }^{65} \mathrm{The}$ risk factors associated with nonadherence to screening were delivering in a public hospital or in a hospital located in the south of Italy, and being a non-Italian woman. ${ }^{65}$

The strategy to reduce vertical transmission cannot be separated from the comprehensive management of the patient. ${ }^{66}$ The first measure is to identify all HBsAg-positive pregnant women by universal screening. Then, subjects who test positive should be evaluated by infectious diseases specialist in order to: 1) evaluate the stage of the HBVrelated liver disease, and therefore the indication for therapy irrespective of the pregnancy status; and 2) quantify the level of HBV-DNA and determine the HBeAg status, and therefore the risk of vertical transmission of HBV. In case of the absence of significant liver disease (ie, the absence of signs of cirrhosis, normal levels of alanine aminotransferase, a normal liver panel, as well as normal platelet levels, and a normal ultrasound examination), the woman should be monitored for possible flares of liver enzymes, with particular attention being paid regarding the risk of vertical transmission to the newborn based on HBV-DNA level. In contrast, in the event that the mother is affected by significant liver disease, antiviral treatment should be started immediately and continued even throughout life. In case of high levels of HBV-DNA (HBV-DNA $>10^{6} \mathrm{IU} / \mathrm{mL}$ ), prophylaxis with antiviral drugs starting around 28 weeks of gestation should be considered.

Regarding the choice of antivirals, both telbivudine and tenofovir are recommended as they are in pregnancy class B. However, because women affected by active liver disease must continue treatment after delivery, we suggest treatment with an analog that has a high barrier to resistance - namely, tenofovir rather than telbivudine, which has a low barrier to resistance ${ }^{47}$ For simple prophylaxis (to be withdrawn 4 weeks after delivery), both analogs can be used because the duration of treatment is associated with a very low risk of resistance. It is noteworthy that if antivirals are administered during pregnancy, breastfeeding is not recommended because of the potential exposure of infants to these drugs. ${ }^{2,21}$

Another case is that of a woman who is undergoing treatment with antivirals when pregnancy is discovered. In such cases, treatment should be switched to a class B drug or treatment should be withdrawn. Based on the safety data of class B drugs, ${ }^{39,67}$ we would suggest that the first option should be to avoid suspension-related reactivation of liver disease and an increase in the maternal viral load that might increase the risk of HBV transmission.

\section{Conclusion}

In conclusion, the universal screening of pregnant women for HBsAg and passive/active prophylaxis to newborns from HBV-positive mothers is an effective measure through which to prevent vertical transmission. In case of a high maternal viral load, third trimester prophylaxis with a class B drug (telbivudine or tenofovir) is able to further reduce the risk of vertical transmission. Large, appropriately designed trials are needed to identify the best drug to use in the different clinical situations.

\section{Acknowledgments}

The authors thank Jean Ann Gilder (Scientific Communication Srl, Naples, Italy) for text editing. The work was partially funded by the fellowship program, "Monitoraggio e gestione clinico-farmacologica delle gravida HBV-positive. Studio prospettico" (Gilead Sciences).

\section{Disclosure}

The authors report no conflicts of interest in this work.

\section{References}

1. World Health Organization [webpage on the Internet]. Hepatitis B Geneva, Switzerland: World Health Organization; 2013 [updated July 2013]. Available from: http://www.who.int/mediacentre/factsheets/ fs204/en/index.html. Accessed May 30, 2014.

2. Borgia G, Carleo MA, Gaeta GB, Gentile I. Hepatitis B in pregnancy. World J Gastroenterol. 2012;18(34):4677-4683.

3. Jonas MM. Hepatitis B and pregnancy: an underestimated issue. Liver Int. 2009;29 Suppl 1:133-139.

4. Lavanchy D. Chronic viral hepatitis as a public health issue in the world. Best Pract Res Clin Gastroenterol. 2008;22(6):991-1008.

5. Coppola N, Loquercio G, Tonziello G, et al. HBV transmission from an occult carrier with five mutations in the major hydrophilic region of HBsAg to an immunosuppressed plasma recipient. J Clin Virol. 2013; 58(1):315-317.

6. Coppola N, Tonziello G, Colombatto P, et al. Lamivudine-resistant HBV strain rtM204V/I in acute hepatitis B. J Infect. 2013;67(4):322-328. 
7. Coppola N, Masiello A, Tonziello G, et al. Factors affecting the changes in molecular epidemiology of acute hepatitis B in a Southern Italian area. J Viral Hepat. 2010;17(7):493-500.

8. Borgia G, Gentile I. Treating chronic hepatitis B: today and tomorrow. Curr Med Chem. 2006;13(23):2839-2855.

9. Coppola N, Marrone A, Pisaturo M, et al. Role of interleukin 28-B in the spontaneous and treatment-related clearance of $\mathrm{HCV}$ infection in patients with chronic HBV/HCV dual infection. Eur J Clin Microbiol Infect Dis. 2014;33(4):559-567.

10. Coppola N, Potenza N, Pisaturo M, et al. Liver microRNA hsa-miR125a-5p in HBV chronic infection: correlation with HBV replication and disease progression. PLoS One. 2013;8(7):e65336.

11. Sagnelli E, Stroffolini T, Mele A, et al. Impact of comorbidities on the severity of chronic hepatitis B at presentation. World J Gastroenterol. 2012;18(14):1616-1621.

12. Sagnelli E, Stroffolini T, Mele A, Imparato M, Almasio PL; Italian Hospitals' Collaborating Group. Chronic hepatitis B in Italy: new features of an old disease - approaching the universal prevalence of hepatitis B e antigen-negative cases and the eradication of hepatitis D infection. Clin Infect Dis. 2008;46(1):110-113.

13. Terrier B, Cacoub P. [Hepatitis B virus, extrahepatic immunologic manifestations and risk of viral reactivation]. Rev Med Interne. 2011;32(10):622-627. French.

14. Cacoub P, Terrier B. Hepatitis B-related autoimmune manifestations. Rheum Dis Clin North Am. 2009;35(1):125-137.

15. Boglione L, D'Avolio A, Cariti G, Di Perri G. Telbivudine in the treatment of hepatitis B-associated cryoglobulinemia. J Clin Virol. 2013;56(2):167-169.

16. Fusco F, D'Anzeo G, Rossi A, et al. Erectile dysfunction in patients with chronic viral hepatitis: a systematic review of the literature. Expert Opin Pharmacother. 2013;14(18):2533-2544.

17. Yin Y, Wu L, Zhang J, Zhou J, Zhang P, Hou H. Identification of risk factors associated with immunoprophylaxis failure to prevent the vertical transmission of hepatitis B virus. $J$ Infect. 2013;66(5): $447-452$.

18. Xu H, Zeng T, Liu JY, et al. Measures to reduce mother-to-child transmission of Hepatitis B virus in China: a meta-analysis. Dig Dis Sci. 2014;59(2):242-258.

19. Papaevangelou V. Perinatal HBV viremia in newborns of $\mathrm{HBsAG}(+)$ mothers is a transient phenomenon that does not necessarily imply HBV infection transmission. J Clin Virol. 2012;54(2):202.

20. Wang JS, Chen H, Zhu QR. Transformation of hepatitis B serologic markers in babies born to hepatitis B surface antigen positive mothers. World J Gastroenterol. 2005;11(23):3582-3585.

21. Piratvisuth T. Optimal management of HBV infection during pregnancy. Liver Int. 2013;33 Suppl 1:188-194.

22. Degli Esposti S, Shah D. Hepatitis B in pregnancy: challenges and treatment. Gastroenterol Clin North Am. 2011;40(2):355-372, viii.

23. Kumar A. Hepatitis B virus infection and pregnancy: a practical approach. Indian J Gastroenterol. 2012;31(2):43-54.

24. Wong VC, Ip HM, Reesink HW, et al. Prevention of the HBsAg carrier state in newborn infants of mothers who are chronic carriers of HBsAg and $\mathrm{HBe} A g$ by administration of hepatitis-B vaccine and hepatitis-B immunoglobulin. Double-blind randomised placebo-controlled study. Lancet. 1984;1(8383):921-926.

25. Lee C, Gong Y, Brok J, Boxall EH, Gluud C. Effect of hepatitis B immunisation in newborn infants of mothers positive for hepatitis B surface antigen: systematic review and meta-analysis. BMJ. 2006; 332(7537):328-336.

26. Bzowej NH. Optimal management of the hepatitis B patient who desires pregnancy or is pregnant. Curr Hepat Rep. 2012;11(2):82-89.

27. Wen WH, Chang MH, Zhao LL, et al. Mother-to-infant transmission of hepatitis B virus infection: significance of maternal viral load and strategies for intervention. J Hepatol. 2013;59(1):24-30.

28. Wiseman E, Fraser MA, Holden S, et al. Perinatal transmission of hepatitis B virus: an Australian experience. Med J Aust. 2009;190(9): 489-492.
29. Zou H, Chen Y, Duan Z, Zhang H, Pan C. Virologic factors associated with failure to passive-active immunoprophylaxis in infants born to HBsAg-positive mothers. J Viral Hepat. 2012;19(2):e18-e25.

30. Godbole G, Irish D, Basarab M, et al. Management of hepatitis B in pregnant women and infants: a multicentre audit from four London hospitals. BMC Pregnancy Childbirth. 2013;13:222.

31. Guo Z, Shi XH, Feng YL, et al. Risk factors of HBV intrauterine transmission among HBsAg-positive pregnant women. $J$ Viral Hepat. 2013;20(5):317-321

32. Xu DZ, Yan YP, Choi BC, et al. Risk factors and mechanism of transplacental transmission of hepatitis B virus: a case-control study. $J$ Med Virol. 2002;67(1):20-26.

33. Zhang SL, Yue YF, Bai GQ, Shi L, Jiang H. Mechanism of intrauterine infection of hepatitis B virus. World J Gastroenterol. 2004;10(3): 437-438.

34. Bai H, Zhang L, Ma L, Dou XG, Feng GH, Zhao GZ. Relationship of hepatitis B virus infection of placental barrier and hepatitis B virus intra-uterine transmission mechanism. World J Gastroenterol. 2007;13(26):3625-3630.

35. Beasley RP, Stevens CE, Shiao IS, Meng HC. Evidence against breastfeeding as a mechanism for vertical transmission of hepatitis B. Lancet. 1975;2(7938):740-741.

36. de Martino M, Appendino C, Resti M, Rossi ME, Muccioli AT, Vierucci A. Should hepatitis B surface antigen positive mothers breast feed? Arch Dis Child. 1985;60(10):972-974.

37. Tseng RY, Lam CW, Tam J. Breastfeeding babies of HBsAg-positive mothers. Lancet. 1988;2(8618):1032.

38. Hill JB, Sheffield JS, Kim MJ, Alexander JM, Sercely B, Wendel GD. Risk of hepatitis B transmission in breast-fed infants of chronic hepatitis B carriers. Obstet Gynecol. 2002;99(6):1049-1052.

39. INC Research. The Antiretroviral Pregnancy Registry Interim Report. Wilmington, NC: INC Research; 2013. Available from: http://www. apregistry.com/forms/interim_report.pdf. Accessed May 30, 2014.

40. van Zonneveld $M$, van Nunen AB, Niesters HG, de Man RA, Schalm SW, Janssen HL. Lamivudine treatment during pregnancy to prevent perinatal transmission of hepatitis B virus infection. $J$ Viral Hepat. 2003;10(4):294-297.

41. Xu WM, Cui YT, Wang L, et al. Lamivudine in late pregnancy to prevent perinatal transmission of hepatitis B virus infection: a multicentre, randomized, double-blind, placebo-controlled study. J Viral Hepat. 2009;16(2):94-103.

42. Ayres A, Yuen L, Jackson KM, et al. Short duration of lamivudine for the prevention of hepatitis B virus transmission in pregnancy: lack of potency and selection of resistance mutations. J Viral Hepat. Epub December 11, 2013

43. Lai CL, Gane E, Liaw YF, et al; Globe Study Group. Telbivudine versus lamivudine in patients with chronic hepatitis B. $N$ Engl J Med. 2007;357(25):2576-2588

44. Liaw YF, Gane E, Leung N, et al; GLOBE Study Group. 2-year GLOBE trial results: telbivudine Is superior to lamivudine in patients with chronic hepatitis B. Gastroenterology. 2009;136(2):486-495.

45. Han GR, Cao MK, Zhao W, et al. A prospective and open-label study for the efficacy and safety of telbivudine in pregnancy for the prevention of perinatal transmission of hepatitis B virus infection. $J$ Hepatol. 2011;55(6):1215-1221.

46. Deng M, Zhou X, Gao S, et al. The effects of telbivudine in late pregnancy to prevent intrauterine transmission of the hepatitis B virus: a systematic review and meta-analysis. Virol J. 2012;9:185.

47. Reynaud L, Carleo MA, Talamo M, Borgia G. Tenofovir and its potential in the treatment of hepatitis B virus. Ther Clin Risk Manag. 2009;5(1):177-185.

48. Pan CQ, Mi LJ, Bunchorntavakul C, et al. Tenofovir disoproxil fumarate for prevention of vertical transmission of hepatitis B virus infection by highly viremic pregnant women: a case series. Dig Dis Sci. 2012;57(9):2423-2429.

49. Celen MK, Mert D, Ay M, et al. Efficacy and safety of tenofovir disoproxil fumarate in pregnancy for the prevention of vertical transmission of HBV infection. World J Gastroenterol. 2013;19(48):9377-9382. 
50. Shi Z, Li X, Ma L, Yang Y. Hepatitis B immunoglobulin injection in pregnancy to interrupt hepatitis B virus mother-to-child transmission-a meta-analysis. Int J Infect Dis. 2010;14(7):e622-e634.

51. Wang J, Zhu Q, Zhang X. Effect of delivery mode on maternal-infant transmission of hepatitis B virus by immunoprophylaxis. Chin Med J (Engl). 2002;115(10):1510-1512.

52. Yang J, Zeng XM, Men YL, Zhao LS. Elective caesarean section versus vaginal delivery for preventing mother to child transmission of hepatitis B virus - a systematic review. Virol J. 2008;5:100.

53. Hu Y, Chen J, Wen J, et al. Effect of elective cesarean section on the risk of mother-to-child transmission of hepatitis B virus. BMC Pregnancy Childbirth. 2013;13(1):119.

54. Newell ML, Bunders MJ. Safety of antiretroviral drugs in pregnancy and breastfeeding for mother and child. Curr Opin HIV AIDS. 2013;8:504-510.

55. Gentile I, Zappulo E, Buonomo AR, Borgia G. Prevention of motherto-child transmission of hepatitis B virus and hepatitis $\mathrm{C}$ virus. Expert Rev Anti Infect Ther. In press 2014.

56. Gentile I, Borgia F, Buonomo AR, Castaldo G, Borgia G. A novel promising therapeutic option against hepatitis $\mathrm{C}$ virus: an oral nucleotide NS5B polymerase inhibitor sofosbuvir. Curr Med Chem. 2013;20(30): 3733-3742.

57. Gentile I, Buonomo AR, Borgia F, Castaldo G, Borgia G. Ledipasvir: a novel synthetic antiviral for the treatment of HCV infection. Expert Opin Investig Drugs. 2014;23(4):561-571.

58. Gentile I, Borgia F, Zappulo E, et al. Efficacy and safety of sofosbuvir in treatment of chronic hepatitis C: the dawn of a new era. Rev Recent Clin Trials. Epub December 13, 2013.
59. Gentile I, Borgia F, Coppola N, Buonomo AR, Castaldo G, Borgia G Daclatasvir: the first of a new class of drugs targeted against hepatitis $\mathrm{C}$ virus NS5A. Curr Med Chem. 2014;21(12):1391-1404.

60. Lange CM, Zeuzem S. Perspectives and challenges of interferon-free therapy for chronic hepatitis C. J Hepatol. 2013;58(3):583-592.

61. Stedman CA. Current prospects for interferon-free treatment of hepatitis C in 2012. J Gastroenterol Hepatol. 2013;28(1):38-45.

62. Gentile I, Buonomo AR, Borgia F, Zappulo E, Castaldo G, Borgia G. MK-5172: a second-generation protease inhibitor for the treatment of hepatitis C virus infection. Expert Opin Investig Drugs. 2014;23(5): 719-728.

63. Chen SC, Toy M, Yeh JM, Wang JD, Resch S. Cost-effectiveness of augmenting universal hepatitis B vaccination with immunoglobin treatment. Pediatrics. 2013;131(4):e1135-e1143.

64. Chen HL, Lin LH, Hu FC, et al. Effects of maternal screening and universal immunization to prevent mother-to-infant transmission of HBV. Gastroenterology. 2012;142(4):773-781. e2.

65. Spada E, Tosti ME, Zuccaro O, Stroffolini T, Mele A; Collaborating Study Group. Evaluation of the compliance with the protocol for preventing perinatal hepatitis B infection in Italy. J Infect. 2011;62(2): $165-171$.

66. Nardiello S, Orsini A, Gentile I, Gaeta GB. [HBV and pregnancy]. Infez Med. 2011;19(3):139-145. Italian.

67. Liu M, Cai H, Yi W. Safety of telbivudine treatment for chronic hepatitis B for the entire pregnancy. J Viral Hepat. 2013;20 Suppl 1: $65-70$.
International Journal of Women's Health

\section{Publish your work in this journal}

The International Journal of Women's Health is an international, peerreviewed open-access journal publishing original research, reports, editorials, reviews and commentaries on all aspects of women's healthcare including gynecology, obstetrics, and breast cancer. The manuscript management system is completely online and includes

\section{Dovepress}

a very quick and fair peer-review system, which is all easy to use. Visit http://www.dovepress.com/testimonials.php to read real quotes from published authors. 